\title{
Association of NOS1 gene polymorphisms with cerebral palsy in a Han Chinese population: a case-control study
}

Ting Yu ${ }^{1+} \mathbb{D}$, Lei Xia ${ }^{2 \dagger}$, Dan $\mathrm{Bi}^{2}$, Yangong Wang ${ }^{1}$, Qing Shang ${ }^{3}$, Dengna Zhu², Juan Song ${ }^{2}$, Yong Wang ${ }^{2}$, Xiaoyang Wang ${ }^{2,4}$, Changlian Zhu ${ }^{2,5^{*}}$ and Qinghe Xing ${ }^{1,6^{*}}$

\begin{abstract}
Background: Cerebral palsy (CP) is the leading cause of motor disability in children; however, its pathogenesis is unknown in most cases. Growing evidence suggests that Nitric oxide synthase 1 (NOS1) is involved in neural development and neurologic diseases. The purpose of this study was to determine whether genetic variants of NOS1 contribute to CP susceptibility in a Han Chinese population.

Methods: A case-control study involving $652 \mathrm{CP}$ patients and 636 healthy controls was conducted. Six SNPs in the NOS1 gene (rs3782219, rs6490121, rs2293054, rs10774909, rs3741475, and rs2682826) were selected, and the MassARRAY typing technique was applied for genotyping. Data analysis was conducted using SHEsis online software, and multiple test corrections were performed using SNPSpD online software.

Results: There were no significant differences in genotype and allele frequencies between patients and controls for the SNPs except rs6490121, which deviated from Hardy-Weinberg equilibrium and was excluded from further analyses. Subgroup analysis revealed differences in genotype frequencies between the CP with neonatal encephalopathy group $(C P+N E)$ and control group for rs10774909, rs3741475, and rs2682826 (after SNPSpD correction, $p=0.004,0.012$, and 0 . 002 , respectively). The T allele of NOS1 SNP rs3782219 was negatively associated with spastic quadriplegia (OR $=0.742$, $95 \% \mathrm{Cl}=0.600-0.918$, after SNPSpD correction, $p=0.023$ ). There were no differences in allele or genotype frequencies between CP subgroups and controls for the other genetic polymorphisms.
\end{abstract}

Conclusions: NOS1 is associated with CP + NE and spastic quadriplegia, suggesting that NOS1 is likely involved in the pathogenesis of $\mathrm{CP}$ and that it is a potential therapeutic target for treatment of cerebral injury.

Keywords: Cerebral palsy, Nitric oxide synthase 1, Single nucleotide polymorphism, Association analysis

\section{Background}

Cerebral palsy (CP), the most common cause of motor disability in childhood, is a group of permanent movement and posture disorders attributed to non-progressive abnormalities in the immature brain. Patients with CP often exhibit secondary musculoskeletal problems, epilepsy, and disturbances of sensation, perception, cognition, communication, and behavior [1]. Epidemiologic studies indicate

\footnotetext{
* Correspondence: zhuc@zzu.edu.cn; xingqinghe@hotmail.com

${ }^{\dagger}$ Ting Yu and Lei Xia contributed equally to this work.

${ }^{2}$ Henan Key Laboratory of Child Brain Injury, Third Affiliated Hospital of

Zhengzhou University, Kangfuqian Street 7, Zhengzhou 450052, China

${ }^{1}$ Children's Hospital and Institutes of Biomedical Sciences, Fudan University,

Wanyuan Road 399, Minhang District, Shanghai 201102, China

Full list of author information is available at the end of the article
}

that the incidence of CP is approximately 2-3 per 1000 live births. Despite remarkable advances in obstetric and neonatal care, the overall prevalence of $\mathrm{CP}$ has changed little over the past several decades [2]. CP is a lifelong neurologic motor disorder and has a substantial impact on health care and social services costs, family welfare, and patient quality of life $[3,4]$. Although known risk factors include prematurity, asphyxia, infection and inflammation, the causes of $\mathrm{CP}$ are unknown in most individuals $[5,6]$. The pathogenesis and mechanism of $\mathrm{CP}$ have been studied and debated for more than 100 years, but the exact pathogenesis remains unclear. Many children with cerebral palsy do not have any known risk factor. Recently, families, twins, population-based, $\mathrm{CNV}$ and

(C) The Author(s). 2018 Open Access This article is distributed under the terms of the Creative Commons Attribution 4.0 International License (http://creativecommons.org/licenses/by/4.0/), which permits unrestricted use, distribution, and 
gene-association studies have strongly and directly suggested that genetic factors contribute to the etiology of CP [7-10].

$\mathrm{CP}$ is a complex disease. It is highly heterogeneous with regard to phenotype and etiology, and the different subtypes of CP might result from different causal pathways. Some cases may be caused by a single mutation in a single gene, but many may be caused by complex interactions of multiple genetic loci and environmental factors. However, the causes of $\mathrm{CP}$ are unknown in most individuals. An increasing association studies have explored the interactions between the susceptibility to $\mathrm{CP}$ and SNPs of candidate genes, including those involved in the inflammatory system and the coagulation cascade such as coagulation factor II/V/VII, lymphotoxin-alpha, tumor necrosis factor, IL-6, and IL-8, to determine whether they contribute to the causal pathway of CP [11-14].

Nitric oxide (NO) acts as a pleiotropic gaseous messenger molecule, and it is dynamically controlled during normal development and brain injuries. NO is synthesized from L-arginine by nitric oxide synthase enzymes (NOSs), of which there are three isozyme forms: neuronal NOS (nNOS, NOS1), inducible NOS (iNOS), and endothelial NOS (eNOS) [15]. The NOS1 gene is the major isoform and is widely expressed throughout the brain, accounting for approximately $90 \%$ of NO in the CNS [16]. NO produced from NOS1 is involved in neurogenesis, neuronal differentiation and development [17, 18], and neuroprotection and neuropathology [19]. NO appears to play a critical role in hypoxia-ischemia (HI) brain injury which is a well-known risk factor for CP [20]. During hypoxic insults, excessive NO, which is produced by NOS1 in the cerebral tissue, produces toxic effects leading to neuronal death through several different mechanisms, such as the $\mathrm{N}$-methyl- $\mathrm{D}$-aspartic acid (NMDA) pathway. NMDA play a role in the pathology of multiple neurodegenerative diseases, such as Alzheimer's, Parkinson's and Multiple Sclerosis [21]. Recent studies have revealed that NOS1 variants are associated with disorders such as Alzheimer's disease [22], schizophrenia [23], and Parkinson's disease [24]. The association of NOS1 with different diseases suggests a pleiotropic role of NOS1 in many physiological processes and a potentially shared pathomechanism.

Genetic and pharmacological studies have also provided valuable insights into the pathophysiology of NOS1. In a neonatal animal model of hypoxia-ischemia (HI), NOS1 knockout mice were less vulnerable to HI-induced histopathological brain damage than their wild-type counterparts [25]. Selective inhibitors of NOS1, which reduce the NO concentration, were shown to dramatically improve the survival rate of fetal rabbits and ameliorate the symptoms of CP [26]. These results strongly suggest that NOS1 might be involved in the pathogenesis of $\mathrm{CP}$. Although biological plausability for the involvement of $\mathrm{NO}$ in the pathogenesis of cerebral palsy is not clear. To our knowledge, no study has reported an association between the NOS1 gene and CP. Therefore, we performed a comprehensive association study on polymorphisms of the NOS1 gene and the risk of different subtypes of $\mathrm{CP}$.

\section{Methods}

\section{Study population}

This was a case-control study based on a Chinese Han population. The study cohort included $652 \mathrm{CP}$ patients and 636 healthy participants who were recruited from the centers for $\mathrm{CP}$ rehabilitation and Child Healthcare Departments in the Third Affiliated Hospital of Zhengzhou University, Zhengzhou Children's Hospital and the First Affiliated Hospital of Henan Traditional Chinese Medical College. The CP group consisted of 198 female (30.4\%) and 454 male (69.6\%) patients ranging in age from 8 to 116 months. The control group was selected from healthy individuals who came to the facility for routine examinations and did not have neurologic conditions or predefined medical conditions; this group was comprised of 214 female (33.2\%) and 422 male (66.8\%) individuals ranging in age from 8 to 106 months. The diagnosis of $\mathrm{CP}$ was made by child neurologists, based on either a clinical examination or medical records and followed the guidelines proposed by the "Surveillance of $\mathrm{CP}$ in Europe" network [27]. Written informed consent was obtained from the parents or guardians on behalf of the infant participants. The study was approved by the Ethics Committee of Zhengzhou University.

The database of medical records contains information on the subtypes of $\mathrm{CP}$, such as spastic; $\mathrm{CP}$ risk factors, such as preterm and birth asphyxia; symptoms concomitant with $\mathrm{CP}$, such as mental retardation (MR); neonatal complications, such as periventricular leukomalacia (PVL) and hypoxic-ischemic encephalopathy (HIE); maternal factors, such as premature rupture of membrane (PROM); and neonatal encephalopathy (NE) (Table 1). The evaluation standards were consistent with those in our previous published study [13]. NE is a clinical syndrome of disordered neurological function, which includes not only HIE but also intracranial hemorrhage, hypoglycemia, severe hyperbilirubinemia, various metabolic disorders, neurodegenerative disorders, and intracranial infection, among other disorders [28].

\section{SNP selection and genotyping}

Altogether, six SNPs (rs3782219, rs6490121, rs2293054, rs10774909, rs3741475, and rs2682826) of the NOS1 gene with minor allele frequencies in the Chinese Han population greater than 0.1 were selected from the 
Table 1 Clinical characteristics of all participants

\begin{tabular}{|c|c|c|}
\hline Characteristic & CP cases $(n=652)$ & Controls $(n=636)$ \\
\hline Sex (male:female) & $454: 198$ & $422: 214$ \\
\hline Preterm (<37 weeks) & 37 & 9 \\
\hline$<2500 \mathrm{~g}$ & 30 & 2 \\
\hline BIRTH Asphyxia & 187 & 11 \\
\hline \multicolumn{3}{|l|}{ TYPE OF CP } \\
\hline Spastic CP & 438 & - \\
\hline $\mathrm{CP}$ with spastic tetraplegia & 238 & - \\
\hline \multicolumn{3}{|l|}{ COMPLICATION } \\
\hline $\mathrm{CP}$ with PVL & 54 & - \\
\hline $\mathrm{CP}$ with HIE & 91 & - \\
\hline $\mathrm{CP}$ with $\mathrm{MR}$ & 248 & - \\
\hline CP with NE & 261 & - \\
\hline \multicolumn{3}{|l|}{ MATERNAL FACTORS } \\
\hline PROM & 62 & 24 \\
\hline TPL & 50 & 27 \\
\hline $\mathrm{PIH}$ & 22 & 5 \\
\hline
\end{tabular}

CP cerebral palsy, PVL periventricular leukomalacia, HIE hypoxic-ischemic encephalopathy, MR mental retardation, NE neonatal encephalopathy, $P R O M$ premature rupture of membrane, TPL threatened premature labor, $P I H$ pregnancyinduced hypertensio

dbSNP database (www.ncbi.nlm.nih.gov/SNP) and the phase II genotyping data of the HapMap project (http://www.1000genomes.org/). rs2293052 (exon 13) and rs3741475 (exon 22) were synonymous mutation, rs2682826 is located in 3'UTR, while the other three SNPs are located in intron: rs3782219 (intron 1), rs6490121 (intron 10), 10,774,909 (intron 20). Exception for rs10774909, the rest 5 SNPs were reported in published literature online, which were associated with disorders, such as Schizophrenia, Alzheimer's disease, Parkinson's disease.

Genomic DNA was extracted from whole blood of $\mathrm{CP}$ patients and controls, using the AxyPrep Blood Genomic DNA Miniprep Kit (Axygen Biosciences, Union City, CA, USA) according to a standard protocol. Probes and primers were designed using the SEQUENOM online tools (https:// http://www.sequenom.com), and the sequences are available upon request. After the amplification of polymorphismspanning fragments by multiplex polymerase chain reaction (PCR), the selected SNPs were genotyped using the MassARRAY system (Sequenom, Inc., San Diego, CA) following the manufacturer's directions (http:// www.sequenom.com). SpectroTYPER software (Sequenom, Inc.) was used to automatically perform genotype calling with a set of digital filters optimized for the mass spectra of oligonucleotides. The individual who analyzed the genotype results was blinded to the clinical data.

\section{Statistical analysis}

Hardy-Weinberg equilibrium testing was performed to analyze the allele and genotype frequencies, using the SHEsis online software platform (http://analysis.bio-x.cn/). Linkage disequilibrium was measured using standardized D', and the discrepancies in allele and genotype frequencies at single loci between patients and controls were compared using a Monte Carlo simulation strategy. The number of observations for each haplotype were compared by $\mathrm{x}^{2}$ tests. All reported $p$ values are two-tailed, and statistical significance was set at $p<0.05$. The relative risk was approximated by the estimate of odds ratio (OR), and for each OR, a 95\% confidence interval $(\mathrm{CI})$ was computed. All statistical analyses were performed using the Statistical Package for the Social Sciences (SPSS version 19.0) and GraphPad Prism 6.0 software package (version 6.0 for Windows, GraphPad, La Jolla, CA, USA). For all comparisons, multiple testing for each individual SNP was corrected using the SNPSpD program (http://gump.qimr.edu.au/general/ daleN/matSpD/), which is based on the linkage disequilibrium. Multiple testing for each haplotype was corrected by the Bonferroni correction. Statistical efficacy was evaluated with G.power 3.1 software.

\section{Results}

\section{Overall analysis}

Power analysis showed that the current sample size had > $85 \%$ power for testing a significant association $(a<0.05)$ when an effect size index of 0.1 was used. The genotypic distribution of the selected SNPs, except for rs6490121 ( $p=0.0338)$, did not deviate from Hardy-Weinberg equilibrium $(p>0.05)$ among the control population (Table 2). Therefore, rs6490121 was excluded from further tests. For the other five SNPs, the genotype frequencies of rs2682826 $(p=0.046)$ were different between all CP patients and the controls, but the differences disappeared after SNPSpD correction (Table 2). There were no significant differences in the allele and genotype frequencies of rs3782219, rs6490121, rs3741475, rs10774909, and rs2293054 between CP cases and controls.

The SNP pairs rs3741475/rs2682826, rs3741475/ rs10774909, and rs10774909/rs2682826 exhibited strong linkage disequilibrium (LD) (D'>0.9) (Additional file 1: Table S1). Haplotype analysis is a powerful strategy for resolving the controversy regarding association studies based on individual polymorphisms and determining whether the SNPs would have greater predictive value when analyzed together. We analyzed only the common haplotypes comprised of rs10774909, rs3741475, and rs2682826 (those with frequency $<0.01$ were excluded from the analysis), but no statistically significant difference was found between all patients and controls (data not shown). 
Table 2 Allele and genotype frequencies of SNPs in CP patients and controls

\begin{tabular}{|c|c|c|c|c|c|c|c|c|c|}
\hline \multirow{2}{*}{$\begin{array}{l}\text { Group } \\
\text { rs3782219 }\end{array}$} & \multicolumn{2}{|c|}{ Allele frequency } & \multirow[t]{2}{*}{$P$} & \multirow[t]{2}{*}{ OR $(95 \% \mathrm{Cl})$} & \multicolumn{3}{|c|}{ Genotype frequency } & \multirow[t]{2}{*}{$P$} & \multirow{2}{*}{$\begin{array}{l}\text { Hardy-Weinbers } \\
\text { equilibrium test }\end{array}$} \\
\hline & $C$ & $T$ & & & $\mathrm{C} / \mathrm{C}$ & & $\mathrm{T} / \mathrm{T}$ & & \\
\hline Case & $764(0.586)$ & $540(0.414)$ & 0.242 & 0.910 & $216(0.331)$ & & $104(0.160)$ & 0.354 & 0.936 \\
\hline Control & $774(0.608)$ & $498(0.392)$ & & $(0.778 \sim 1.066)$ & $235(0.369)$ & 0.939 & $97(0.153)$ & & \\
\hline rs6490121 & $A$ & G & & & $\mathrm{A} / \mathrm{A}$ & & GG & & \\
\hline Case & $831(0.637)$ & $473(0.363)$ & 0.888 & 0.989 & $268(0.411)$ & & $89(0.137)$ & 0.585 & 0.0470 \\
\hline Control & $814(0.640)$ & $458(0.360)$ & & $(0.842 \sim 1.1609)$ & $272(0.428)$ & 0.047 & $94(0.148)$ & & \\
\hline rs2293054 & A & G & & & $\mathrm{A} / \mathrm{A}$ & & $\mathrm{G} / \mathrm{G}$ & & \\
\hline Case & $270(0.207)$ & $1034(0.793)$ & 0.607 & 1.052 & $29(0.044)$ & & $411(0.630)$ & 0.877 & 0.204 \\
\hline Control & $253(0.199)$ & $1019(0.801)$ & & $(0.868 \sim 1.274)$ & $26(0.041)$ & 0.204 & $409(0.643)$ & & \\
\hline rs10774909 & C & G & & & $\mathrm{C} / \mathrm{C}$ & & $\mathrm{G} / \mathrm{G}$ & & \\
\hline Case & $887(0.680)$ & $417(0.320)$ & 0.958 & 1.004463 & $293(0.449)$ & & $58(0.089)$ & 0.496 & 0.107 \\
\hline Control & 864 (0.679) & $408(0.321)$ & & $(0.8512 \sim 1.185)$ & $294(0.462)$ & 0.107 & $66(0.104)$ & & \\
\hline rs3741475 & A & G & & & $\mathrm{A} / \mathrm{A}$ & & $\mathrm{G} / \mathrm{G}$ & & \\
\hline Case & $335(0.257)$ & $969(0.743)$ & 0.519 & 0.944 & $35(0.054)$ & & $352(0.540)$ & 0.094 & 0.918 \\
\hline Control & $341(0.268)$ & $931(0.732)$ & & $(0.792 \sim 1.125)$ & $52(0.082)$ & 0.918 & $347(0.546)$ & & \\
\hline rs 2682826 & A & G & & & $\mathrm{A} / \mathrm{A}$ & & $\mathrm{G} / \mathrm{G}$ & & \\
\hline Case & $335(0.257)$ & $969(0.743)$ & 0.709 & 0.967 & $34(0.052)$ & & $351(0.538)$ & 0.046 & 0.835 \\
\hline Control & $335(0.263)$ & 937 (0.737) & & $(0.811 \sim 1.153)$ & $52(0.082)$ & 0.835 & $353(0.555)$ & & \\
\hline
\end{tabular}

\section{Subgroup analysis}

$\mathrm{CP}$ is highly heterogeneous with regard to clinical presentation, etiology, and pathogenesis. Subgroup analysis was performed to evaluate the potential relationship between genotypes and clinical features such as sex, gestational age, CP subtype, and neonatal complications (Tables 3, 4 and 5). The results of the subgroup analysis indicated significant differences in the allele or genotype frequencies in these $\mathrm{CP}$ subgroups, including male sex, birth asphyxia, spastic type, spastic tetraplegia, and NE. However, the associations of rs3741475 and rs2682826 with male CP, rs10774909 with $\mathrm{CP}+$ birth asphyxia, and rs2682826 with spastic CP disappeared after adjusting for multiple tests, using the program

Table 3 Allele and genotype frequencies of SNPs in CP patients with spastic tetraplegia and controls

\begin{tabular}{|c|c|c|c|c|c|c|c|c|}
\hline \multirow{2}{*}{$\begin{array}{l}\text { Group } \\
\text { rs3782219 }\end{array}$} & \multicolumn{2}{|c|}{ Allele frequency } & \multirow[t]{2}{*}{$P$} & \multirow[t]{2}{*}{ OR $(95 \% \mathrm{Cl})$} & \multicolumn{3}{|c|}{ Genotype frequency } & \multirow[t]{2}{*}{$P$} \\
\hline & $C$ & $\mathrm{~T}$ & & & $C / C$ & $\mathrm{C} / \mathrm{T}$ & $\mathrm{T} / \mathrm{T}$ & \\
\hline Case & $255(0.536)$ & $221(0.464)$ & $0.006^{\mathrm{a}}$ & 0.742 & $63(0.265)$ & $129(0.542)$ & $46(0.193)$ & 0.013 \\
\hline Control & 774 (0.608) & $498(0.392)$ & & $(0.600 \sim 0.918)$ & $235(0.369)$ & $304(0.478)$ & $97(0.153)$ & \\
\hline rs2293054 & A & G & & & $\mathrm{A} / \mathrm{A}$ & $A / G$ & $G / G$ & \\
\hline Case & $110(0.231)$ & $366(0.769)$ & 0.140 & 1.211 & $16(0.067)$ & $78(0.328)$ & $144(0.605)$ & 0.226 \\
\hline Control & 253 (0.199) & 1019 (0.801) & & $(0.939 \sim 1.560)$ & $26(0.041)$ & $201(0.316)$ & $409(0.643)$ & \\
\hline rs10774909 & C & G & & & $\mathrm{C} / \mathrm{C}$ & $C / G$ & $\mathrm{G} / \mathrm{G}$ & \\
\hline Case & $328(0.689)$ & $148(0.311)$ & 0.695 & 1.047 & $106(0.445)$ & $116(0.487)$ & $16(0.067)$ & 0.159 \\
\hline Control & 864 (0.679) & $408(0.321)$ & & $(0.834 \sim 1.313)$ & $294(0.462)$ & $276(0.434)$ & $66(0.104)$ & \\
\hline rs3741475 & A & G & & & $\mathrm{A} / \mathrm{A}$ & $A / G$ & $\mathrm{G} / \mathrm{G}$ & \\
\hline Case & $108(0.227)$ & $368(0.773)$ & 0.079 & 0.801 & $8(0.034)$ & $92(0.387)$ & $138(0.580)$ & 0.043 \\
\hline Control & $341(0.268)$ & $931(0.732)$ & & $(0.625 \sim 1.027)$ & $52(0.082)$ & $237(0.373)$ & $347(0.546)$ & \\
\hline rs2682826 & $A$ & G & & & $\mathrm{A} / \mathrm{A}$ & $A / G$ & $\mathrm{G} / \mathrm{G}$ & \\
\hline Case & 109 (0.229) & 367 (0.771) & 0.142 & 0.831 & $8(0.034)$ & $93(0.391)$ & 137 (0.576) & 0.042 \\
\hline Control & $335(0.263)$ & $937(0.737)$ & & $(0.649 \sim 1.064)$ & $52(0.082)$ & $231(0.363)$ & $353(0.555)$ & \\
\hline
\end{tabular}

${ }^{\mathrm{a}}$ After the SNPSpD correction, $p=0.023$ 
Table 4 Haplotype analysis between patients with spastic tetraplegia and controls

\begin{tabular}{lllll}
\hline Haplotype & case(frequency) & control(frequency) & $P$-value & OR(95\% Cl) \\
\hline C G G & $323.66(0.680)$ & $852.26(0.670)$ & 0.745 & $1.039[0.826 \sim$ \\
& & & & $1.306]$ \\
G A A & $103.66(0.218)$ & $324.60(0.255)$ & 0.099 & $0.809[0.629 \sim$ \\
& & & & $1.041]$ \\
G GG & $42.34(0.089)$ & $74.71(0.059)$ & $0.025^{*}$ & $1.561[1.054 \sim$ \\
& & & & $2.312]$ \\
$\begin{array}{l}\text { Global } \\
\text { result }\end{array}$ & & & 0.034 & \\
\hline
\end{tabular}

Abbreviations: $O R$ odds ratio, $\mathrm{Cl}$ confidence interval

Loci chosen for haplotype analysis: rs10774909, rs229305, rs2682826

Haplotype frequency $<0.01$ in both control \& case has been dropped

${ }^{*}$ After Bonferroni correction, $p=0.075$

SNPSpD. There were no differences in allele or genotype frequencies in the other $\mathrm{CP}$ subgroups classified according to gestational age, birth weight, or fetal growth restriction (data not shown).

Notably, the T allele of NOS1 SNP rs3782219 was negatively associated with spastic quadriplegia $(\mathrm{OR}=$ $0.742,95 \% \mathrm{CI}=0.600-0.918$, after SNPSpD correction, $p$ value $=0.023)($ Table 3$)$. The genotype frequencies of $\operatorname{rs} 3782219(p=0.013), \operatorname{rs} 3741475(p=0.043)$, and rs2682826 $(p=0.042)$ also showed differences between spastic tetraplegia $(n=238)$ and controls, but the differences disappeared after SNPSpD correction. The haplotype analysis for rs10774909, rs3741475, and rs2682826 revealed a global $P$-value of 0.034 (Table 4). The haplotype "GGG" was found to be significantly associated with spastic tetraplegia $(\mathrm{OR}=1.561,95 \%$ $\mathrm{CI}=1.054 \sim 2.312, \quad p=0.025), \quad$ but the differences disappeared after Bonferroni correction $(p=0.075)$. There were significant differences in genotype between CP patients with NE $(n=261)$ and controls at rs10774909, rs3741475, and rs2682826 $(p=0.005,0.015$, and 0.003 , respectively, after SNPSpD correction) (Table 5). The haplotype analysis of the three SNPs did not indicate significant differences between $\mathrm{CP}$ patients with NE and control subjects (data not shown).

\section{Discussion}

The present study is the first to link a genetic variant with NOS1 gene to CP. We conducted a case-control study that included $652 \mathrm{CP}$ patients and 636 healthy controls. Given that the sample size was sufficient for an appropriate statistical analysis, the likelihood of a type II error appears to be considerably low. Our result has shown that there was no significant association between NOS1 and susceptibility to CP.

$\mathrm{CP}$ cases are highly heterogeneous with regard to both etiology and clinical phenotype, and different clinical phenotypes may have different pathogenesis [29]. Genetic factors might be associated with certain sub-types of CP [30]. According to the stratified analysis of factors such as sex, gestational age, birth weight, risk factors, clinical classification, complications and others. The T allele of NOS1 SNP rs3782219 was negatively associated with spastic quadriplegia, and the genotype frequencies of rs10774909, rs37841475, and rs2682826 were significantly associated with $\mathrm{CP}+\mathrm{NE}$. Both spastic tetraplegia and $\mathrm{CP}+\mathrm{NE}$ are serious forms of $\mathrm{CP}$, suggesting that NOS1 likely plays a more important role in the pathogenesis of severe CP.

Table 5 Allele and genotype frequencies of SNPs in CP patients with neonatal encephalopathy and controls

\begin{tabular}{|c|c|c|c|c|c|c|c|c|}
\hline \multirow{2}{*}{$\frac{\text { Group }}{\text { rs3782219 }}$} & \multicolumn{2}{|c|}{ Allele frequency } & \multirow[t]{2}{*}{$P$} & \multirow[t]{2}{*}{ OR $(95 \% \mathrm{Cl})$} & \multicolumn{3}{|c|}{ Genotype frequency } & \multirow[t]{2}{*}{ P } \\
\hline & C & $\mathrm{T}$ & & & $\mathrm{C} / \mathrm{C}$ & $\mathrm{C} / \mathrm{T}$ & $\mathrm{T} / \mathrm{T}$ & \\
\hline Case & $300(0.575)$ & $222(0.425)$ & 0.185 & 0.869 & $82(0.314)$ & $136(0.521)$ & $43(0.165)$ & 0.289 \\
\hline Control & 774 (0.608) & $498(0.392)$ & & $(0.707 \sim 1.069)$ & 235 (0.369) & $304(0.478)$ & $97(0.153)$ & \\
\hline rs2293054 & A & G & & & A/A & $A / G$ & $G / G$ & \\
\hline Case & $122(0.234)$ & $400(0.766)$ & 0.100 & 1.228 & $15(0.057)$ & $92(0.352)$ & $154(0.590)$ & 0.256 \\
\hline Control & $253(0.199)$ & 1019 (0.801) & & $(0.961 \sim 1.560)$ & $26(0.041)$ & $201(0.316)$ & 409 (0.643) & \\
\hline rs10774909 & C & G & & & $\mathrm{C} / \mathrm{C}$ & $C / G$ & $\mathrm{G} / \mathrm{G}$ & \\
\hline Case & $343(0.657)$ & $179(0.343)$ & 0.364 & 0.905 & $98(0.375)$ & $147(0.563)$ & $16(0.061)$ & $0.001^{a}$ \\
\hline Control & $864(0.679)$ & $408(0.321)$ & & $(0.729 \sim 1.123)$ & $294(0.462)$ & $276(0.434)$ & $66(0.104)$ & \\
\hline rs3741475 & A & G & & & $\mathrm{A} / \mathrm{A}$ & $A / G$ & $\mathrm{G} / \mathrm{G}$ & \\
\hline Case & $145(0.278)$ & $377(0.722)$ & 0.675 & 1.050 & $10(0.038)$ & $125(0.479)$ & $126(0.483)$ & $0.003^{b}$ \\
\hline Control & $341(0.268)$ & $931(0.732)$ & & $(0.836 \sim 1.319)$ & $52(0.082)$ & 237 (0.373) & 347 (0.546) & \\
\hline rs2682826 & $A$ & G & & & $\mathrm{A} / \mathrm{A}$ & $A / G$ & $\mathrm{G} / \mathrm{G}$ & \\
\hline Case & $145(0.278)$ & $377(0.722)$ & 0.531 & 1.076 & $9(0.034)$ & $127(0.487)$ & $125(0.479)$ & $0.0005^{c}$ \\
\hline Control & $335(0.263)$ & $937(0.737)$ & & $(0.856 \sim 1.352)$ & $52(0.082)$ & $231(0.363)$ & $353(0.555)$ & \\
\hline
\end{tabular}

${ }^{\mathrm{a}}$ After the SNPSpD correction, $p=0.004 ;{ }^{\mathrm{b}}$ After the SNPSpD correction, $p=0.012$; ${ }^{\mathrm{C}}$ After the SNPSpD correction, $p=0.002$ 
The etiology and pathogenesis of NE are not clear, and the known risk factors include HIE, intracranial hemorrhage, hypoglycemia, severe hyperbilirubinemia, a variety of metabolic disorders, neurodegenerative diseases, and intracranial infection [31]. Those also were risk factors for CP. In addition, NOS1 inhibitors can effectively reduce the degree of an ischemic brain injury. In view of the important role of $\mathrm{NO}$ in ischemic brain injuries, the association of the NOS1 gene with $\mathrm{CP}+\mathrm{NE}$ also indirectly suggests that hypoxic brain damage may play an important role in the pathogenesis of $\mathrm{CP}$.

$\mathrm{NO}$ is a highly diffusible gas that easily penetrates biological membranes and participates in a variety of important biological processes in the brain, such as immune responses, the release and delivery of neurotransmitters [32-34]. During intrauterine or hypoxic insults, excessive $\mathrm{NO}$ is produced by NOS1 in the cerebral tissue. Abnormal levels of NO have negative effects on the developing fetal brain through a wide range of mechanisms, such as glutamate and N-methyl-D-aspartate receptor (NMDAR) activation, resulting in excitotoxicity, oxidative stress, and inflammatory responses $[35,36]$. It has been postulated that NMDA receptors play an essential role in the pathogenesis of CP [37, 38]. NMDA receptors are essential for excitatory synaptic transmission in the CNS. During in the process of hypoxic injury, excessive NO trigger the activity of NMDA receptors, leading to intracellular calcium ion influx, lipid peroxidation and free radical production. Those processes ultimately results in neuronal cell injury and irreversible brain damage. NMDA receptors were highly expressed in oligodendrocytes where glutamate toxicity could damage the myelin sheath that implies a role in synaptic stability and neuronal activity $[39,40]$.

The human NOS1 gene is composed of 29 exons and 28 introns and maps to $12 \mathrm{q} 24$, which spans more than a $160 \mathrm{~kb}$ genomic region [41]. Moreover, its expression patterns are associated with the promoter-exon1 region [42]. Associations of NOS1 with various diseases have been reported, such as schizophrenia, Parkinson's disease, suicide, achalasia, multiple sclerosis, ischemic stroke, and hypertension. In previous studies found that the $\mathrm{T}$ allele of rs2293054 was associated with lower NIHSS scores and with NIHSS scores of ischemic stroke patients in different inherited model [43]. But in our result, rs2293054 showed no relationship with CP. To our knowledge only several studies are to investigate the relationship of rs3782219 SNP and rs3741475 with clinical diseases, it showed no relationship with disorders. However, we found the T allele of NOS1 SNP rs3782219 was negatively associated with spastic quadriplegia. The genotype frequencies of rs3741475 was significantly associated with $\mathrm{CP}+\mathrm{NE}$. Therefore, the T-allele of the rs3782219 and genotype of rs3741475 may contribute to the pathogenesis of clinical phenotypes in $\mathrm{CP}$ patients.
The synonymous SNP (rs2682826) located in the 3'-UTR of exon 29 of the NOS1 gene was selected as the tag SNP for one of the most frequent haplotypes. The SNP rs2682826 is located close to several miRNA-binding sites in the gene's 3'-UTR, and it likely affects the stability and translational efficiency of mRNA [4345]. Some polymorphisms in NOS1 gene can directly affect the expression of mRNA, which change the levels of NO [46, 47]. While the majority of SNPs located in intron region do not affect the amino acid sequence, but they may be indirectly involved in the regulation of NOS1 expression or might be in linkage disequilibrium with a functional site. Rujescu et al. (2008) reported that the CGG haplotype which consists of 3 SNPs of NOS1 gene including rs2682826 SNP was significantly associated with suicide attempts [48]. The genotype frequencies of rs107749909, rs37841475, and rs2682826 were significantly associated with $\mathrm{CP}+\mathrm{NE}$, respectively. But the haplotype consisted of three highly linkage SNPs was no significantly associated with $\mathrm{CP}+\mathrm{NE}$. Future association studies with more systemic SNPs selection are thought to be needed to clarify the involvement of NOS1 in CP.

The etiology and pathogenesis of $\mathrm{CP}$ are complex. Regarding the genetic mechanism, CP may exhibit different genetic patterns, and the disease is polygenic in most $\mathrm{CP}$ cases. Although genome-wide association studies (GWASs) have been successful in identifying many cerebral disorder-associated loci, no GWAS on $\mathrm{CP}$ has been performed, and most of the CP-related genes have not been identified. Because of the complicated genetic architecture of $\mathrm{CP}$, multiple genes might be involved in the etiology of $\mathrm{CP}$, and the effect size of each individual risk allele is likely to be small. Moreover, the factors underlying inter-individual variations in the susceptibility to CP may also include demographic, clinical, and environmental variables. Our results need to be validated or replicated in other, larger population samples.

\section{Conclusions}

There was no significant association between NOS1 gene polymorphisms and $\mathrm{CP}$ at the total level, but NOS1 was associated with spastic tetraplegia and $\mathrm{CP}+\mathrm{NE}$, suggesting that NOS1 may play a more important role in the pathogenesis of severe forms of CP. However, we only assessed five SNPs of the NOS1 gene, and it is necessary to explore more NOS1 gene variants. It is important to note that a comprehensive evaluation of the NOS1 gene and $\mathrm{CP}$ requires a large sample for which sample independence can be validated and functional evidence is available. Furthermore, functional studies on the impact of these polymorphisms on gene expression in $\mathrm{CP}$ populations might help to define new therapeutic perspectives for $\mathrm{CP}$. 


\section{Additional file}

Additional file 1: Table S1. Linkage disequilibrium among the five SNPS. The standardized $D^{\prime}$ values are shown above the diagonal, and the $r 2$ values are shown below the diagonal. (DOCX $12 \mathrm{~kb}$ )

\section{Abbreviations}

Cl: Confidence interval; CP: Cerebral palsy; HWE: Hardy-weinberg equilibrium; MAF: Minor allele frequency; NE: Neonatal encephalopathy; NOS1: Nitric oxide synthase 1; OR: Odds ratio; SNP: Single nucleotide polymorphism

\section{Acknowledgements}

We thank all participants involved in this study and all authors.

\section{Funding}

This work was supported by the Shanghai Municipal Commission of Science and Technology Program (14DJ1400101), the Fourth Round of Shanghai Three-year Action Plan on Public Health Discipline and Talent Program: Women and Children's Health (No. 15GWZK0401), the National Natural Science Foundation of China (grants 31611130035,31371274, U1604165), VINNMER-Marie Curie international qualification (VINNOVA, 2015-04780), the Swedish Medical Research Council (VR 2015-06276), Swedish governmental grants to researchers in the public health service (ALFGBG-429271) and the 973 Projects (2011CB710801). The funding sponsors had no role in the design of the study, collection, analysis and interpretation of data and in writing the manuscript.

\section{Availability of data and materials}

The datasets used and analysed during the current study are available from the corresponding author on reasonable request.

\section{Authors' contributions}

QX and CZ conceived and designed the study. LX, QS, DZ, JS, YW and XW recruited subjects and sorted out clinical information. YW and DB performed all of the laboratory work. TY performed all data and statistical analysis. YT drafted the manuscript. All authors have read and approved the final manuscript.

\section{Ethics approval and consent to participate}

Written informed consent was obtained from the parents or guardians on behalf of the infant participants. The study was approved by the Ethics Committee of Zhengzhou University and the Medical Academy of Henan Province in accordance with the principles of the Declaration of Helsinki.

\section{Consent for publication}

Not applicable.

\section{Competing interests}

The authors declare that they have no competing interests.

\section{Publisher's Note}

Springer Nature remains neutral with regard to jurisdictional claims in published maps and institutional affiliations.

\footnotetext{
Author details

${ }^{1}$ Children's Hospital and Institutes of Biomedical Sciences, Fudan University, Wanyuan Road 399, Minhang District, Shanghai 201102, China. ${ }^{2}$ Henan Key Laboratory of Child Brain Injury, Third Affiliated Hospital of Zhengzhou University, Kangfuqian Street 7, Zhengzhou 450052, China. ${ }^{3}$ Department of Pediatrics, Zhengzhou Children's Hospital, Zhengzhou 450053, China. ${ }^{4}$ Perinatal Center, Institute of Neuroscience and Physiology, University of Gothenburg, Gothenburg 40530, Sweden. ${ }^{5}$ Center for Brain Repair and Rehabilitation, Department of Clinical Neuroscience, Sahlgrenska Academy, University of Gothenburg, Gothenburg 40530, Sweden. ${ }^{6}$ Shanghai Center for Women and Children's Health, Shanghai 200062, China.
}

Received: 13 June 2017 Accepted: 13 June 2018

Published online: 25 June 2018

\section{References}

1. Bax M, Goldstein M, Rosenbaum P, Leviton A, Paneth N, Dan B, Jacobsson B, Damiano D. Proposed definition and classification of cerebral palsy, April 2005. Dev Med Child Neurol. 2005:47(8):571-6.

2. Colver A, Fairhurst C, Pharoah PO. Cerebral palsy. Lancet. 2014;383(9924):1240-9.

3. Tosi LL, Maher N, Moore DW, Goldstein M, Aisen ML. Adults with cerebral palsy: a workshop to define the challenges of treating and preventing secondary musculoskeletal and neuromuscular complications in this rapidly growing population. Dev Med Child Neurol. 2009;51(Suppl 4):2-11.

4. Weichselbraun A, Gindl S, Scharl A. Enriching semantic knowledge bases for opinion mining in big data applications. Knowl Based Syst. 2014;69:78-85.

5. Badawi N, Keogh JM. Causal pathways in cerebral palsy. J Paediatr Child Health. 2013;49(1):5-8.

6. Wu YW, Xing G, Fuentes-Afflick E, Danielson B, Smith LH, Gilbert WM. Racial, ethnic, and socioeconomic disparities in the prevalence of cerebral palsy. Pediatrics. 2011;127(3):e674-81.

7. Rajab A, Yoo SY, Abdulgalil A, Kathiri S, Ahmed R, Mochida GH, Bodell A, Barkovich AJ, Walsh CA. An autosomal recessive form of spastic cerebral palsy (CP) with microcephaly and mental retardation. Am J Med Genet A. 2006;140(14):1504-10.

8. Garne E, Dolk H, Krageloh-Mann I, Holst RS, Cans C. Cerebral palsy and congenital malformations. Eur J Paediatr Neurol. 2008;12(2):82-8.

9. Oskoui M, Gazzellone MJ, Thiruvahindrapuram B, Zarrei M, Andersen J, Wei J, Wang Z, Wintle RF, Marshall CR, Cohn RD, et al. Clinically relevant copy number variations detected in cerebral palsy. Nat Commun. 2015;6:7949.

10. Segel R, Ben-Pazi H, Zeligson S, Fatal-Valevski A, Aran A, Gross-Tsur V, Schneebaum-Sender N, Shmueli D, Lev D, Perlberg S, et al. Copy number variations in cryptogenic cerebral palsy. Neurology. 2015;84(16):1660-8.

11. O'Callaghan ME, Maclennan AH, Gibson CS, McMichael GL, Haan EA, Broadbent JL, Goldwater PN, Painter JN, Montgomery GW, Dekker GA. Fetal and maternal candidate single nucleotide polymorphism associations with cerebral palsy: a case-control study. Pediatrics. 2012;129(2):e414-23.

12. Nelson KB, Dambrosia JM, lovannisci DM, Cheng S, Grether JK, Lammer E. Genetic polymorphisms and cerebral palsy in very preterm infants. Pediatr Res. 2005:57(4):494-9.

13. Bi D, Chen M, Zhang X, Wang H, Xia L, Shang Q, Li T, Zhu D, Blomgren K, $\mathrm{He} L$, et al. The association between sex-related interleukin- 6 gene polymorphisms and the risk for cerebral palsy. J Neuroinflammation. 2014;11:100.

14. Hou R, Ren X, Wang J, Guan X. TNF-alpha and MTHFR polymorphisms associated with cerebral palsy in Chinese infants. Mol Neurobiol. 2016; 53(10):6653-8.

15. Alderton WK, Cooper CE, Knowles RG. Nitric oxide synthases: structure, function and inhibition. Biochem J. 2001;357(Pt 3):593-615.

16. Khaldi A, Chiueh CC, Bullock MR, Woodward JJ. The significance of nitric oxide production in the brain after injury. Ann N Y Acad Sci. 2002;962:53-9.

17. Contestabile A, Ciani E. Role of nitric oxide in the regulation of neuronal proliferation, survival and differentiation. Neurochem Int. 2004;45(6):903-14.

18. Estrada C, Murillo-Carretero M. Nitric oxide and adult neurogenesis in health and disease. Neuroscientist. 2005;11(4):294-307.

19. Contestabile A, Monti B, Contestabile A, Ciani E. Brain nitric oxide and its dual role in neurodegeneration/neuroprotection: understanding molecular mechanisms to devise drug approaches. Curr Med Chem. 2003;10(20):2147-74.

20. Derrick M, Drobyshevsky A, Ji X, Chen L, Yang Y, Ji H, Silverman RB, Tan S. Hypoxia-ischemia causes persistent movement deficits in a perinatal rabbit model of cerebral palsy: assessed by a new swim test. Int J Dev Neurosci. 2009;27(6):549-57.

21. Ma MW, Wang J, Zhang Q, Wang R, Dhandapani KM, Vadlamudi RK, Brann DW. NADPH oxidase in brain injury and neurodegenerative disorders. Mol Neurodegener. 2017;12(1):7.

22. Reif A, Grunblatt E, Herterich S, Wichart I, Rainer MK, Jungwirth S, Danielczyk W, Deckert J, Tragl KH, Riederer P, et al. Association of a functional NOS1 promoter repeat with Alzheimer's disease in the VITA cohort. J Alzheimers Dis. 2011;23(2):327-33.

23. Shinkai T, Ohmori O, Hori H, Nakamura J. Allelic association of the neuronal nitric oxide synthase (NOS1) gene with schizophrenia. Mol Psychiatry. 2002; 7(6):560-3. 
24. Hancock DB, Martin ER, Vance JM, Scott WK. Nitric oxide synthase genes and their interactions with environmental factors in Parkinson's disease. Neurogenetics. 2008;9(4):249-62.

25. Ferriero DM, Holtzman DM, Black SM, Sheldon RA. Neonatal mice lacking neuronal nitric oxide synthase are less vulnerable to hypoxic-ischemic injury. Neurobiol Dis. 1996;3(1):64-71.

26. Ji H, Tan S, Igarashi J, Li H, Derrick M, Martasek P, Roman LJ, Vasquez-Vivar J, Poulos TL, Silverman RB. Selective neuronal nitric oxide synthase inhibitors and the prevention of cerebral palsy. Ann Neurol. 2009;65(2):209-17.

27. Sellier E, Surman G, Himmelmann K, Andersen G, Colver A, Krageloh-Mann I, De-la-Cruz J, Cans C. Trends in prevalence of cerebral palsy in children born with a birthweight of 2,500 g or over in Europe from 1980 to 1998. Eur J Epidemiol. 2010;25(9):635-42.

28. Shang Q, Zhou C, Liu D, Li W, Chen M, Xu Y, Wang F, Bi D, Zhang X, Zhao $X$, et al. Association Between Osteopontin Gene Polymorphisms and Cerebral Palsy in a Chinese Population. Neuromolecular Med. 2016;18(2): 232-8.

29. Chang MC, Jang SH, Yoe SS, Lee E, Kim S, Lee DG, Son SM. Diffusion tensor imaging demonstrated radiologic differences between diplegic and quadriplegic cerebral palsy. Neurosci Lett. 2012;512(1):53-8.

30. Nelson KB. Causative factors in cerebral palsy. Clin Obstet Gynecol. 2008; 51(4):749-62.

31. Battin M, Sadler L, Masson V, Farquhar C. Neonatal encephalopathy in New Zealand: Demographics and clinical outcome. J Paediatr Child Health. 2016; 52(6):632-6

32. Tan S, Zhou F, Nielsen VG, Wang Z, Gladson CL, Parks DA. Sustained hypoxia-ischemia results in reactive nitrogen and oxygen species production and injury in the premature fetal rabbit brain. J Neuropathol Exp Neurol. 1998;57(6):544-53.

33. Tan S, Zhou F, Nielsen VG, Wang Z, Gladson CL, Parks DA. Increased injury following intermittent fetal hypoxia-reoxygenation is associated with increased free radical production in fetal rabbit brain. J Neuropathol Exp Neurol. 1999;58(9):972-81.

34. Baig MS, Zaichick SV, Mao M, de Abreu AL, Bakhshi FR, Hart PC, Saqib U, Deng J, Chatterjee S, Block ML, et al. NOS1-derived nitric oxide promotes NF-kappaB transcriptional activity through inhibition of suppressor of cytokine signaling-1. J Exp Med. 2015;212(10):1725-38.

35. Costantine MM, Clark EA, Lai Y, Rouse DJ, Spong CY, Mercer BM, Sorokin Y, Thorp JJ, Ramin SM, Malone FD, et al. Association of polymorphisms in neuroprotection and oxidative stress genes and neurodevelopmental outcomes after preterm birth. Obstet Gynecol. 2012;120(3):542-50.

36. Buhimschi CS, Baumbusch MA, Dulay AT, Oliver EA, Lee S, Zhao G, Bhandari $\checkmark$, Ehrenkranz RA, Weiner CP, Madri JA, et al. Characterization of RAGE, HMGB1, and S100beta in inflammation-induced preterm birth and fetal tissue injury. Am J Pathol. 2009;175(3):958-75.

37. Wallin C, Puka-Sundvall M, Hagberg H, Weber SG, Sandberg M. Alterations in glutathione and amino acid concentrations after hypoxia-ischemia in the immature rat brain. Brain Res Dev Brain Res. 2000;125(1-2):51-60.

38. Costantine MM, Drever N. Antenatal exposure to magnesium sulfate and neuroprotection in preterm infants. Obstet Gynecol Clin North Am. 2011; 38(2):351-66.

39. Mayer ML. Glutamate receptors at atomic resolution. Nature. 2006;440(7083): 456-62.

40. Karadottir R, Cavelier P, Bergersen LH, Attwell D. NMDA receptors are expressed in oligodendrocytes and activated in ischaemia. Nature. 2005; 438(7071):1162-6.

41. Hall AV, Antoniou H, Wang Y, Cheung AH, Arbus AM, Olson SL, Lu WC, Kau $\mathrm{CL}$, Marsden PA. Structural organization of the human neuronal nitric oxide synthase gene (NOS1). J Biol Chem. 1994;269(52):33082-90.

42. Bros M, Boissel JP, Godtel-Armbrust U, Forstermann U. Transcription of human neuronal nitric oxide synthase mRNAs derived from different first exons is partly controlled by exon 1-specific promoter sequences. Genomics. 2006;87(4):463-73.

43. Yoo SD, Park JS, Yun DH, Kim HS, Kim SK, Kim DH, Chon J, Je G, Kim YS, Chung $\mathrm{JH}$, et al. Polymorphism of nitric oxide synthase 1 affects the clinical phenotypes of ischemic stroke in Korean population. Ann Rehabil Med. 2016:40(1):102-10.

44. Mignone F, Gissi C, Liuni S, Pesole G. Untranslated regions of mRNAs. Genome Biol. 2002;3(3):S4.

45. Chatterjee S, Pal JK. Role of 5'- and 3'-untranslated regions of mRNAs in human diseases. Biol Cell. 2009;101(5):251-62.
46. Reif A, Herterich S, Strobel A, Ehlis AC, Saur D, Jacob CP, Wienker T, Topner T, Fritzen S, Walter U, et al. A neuronal nitric oxide synthase (NOS-I) haplotype associated with schizophrenia modifies prefrontal cortex function. Mol Psychiatry. 2006;11(3):286-300.

47. Fallin MD, Lasseter VK, Avramopoulos D, Nicodemus KK, Wolyniec PS, McGrath JA, Steel G, Nestadt G, Liang KY, Huganir RL, et al. Bipolar I disorder and schizophrenia: a 440-single-nucleotide polymorphism screen of 64 candidate genes among Ashkenazi Jewish case-parent trios. Am J Hum Genet. 2005;77(6):918-36.

48. Rujescu D, Giegling I, Mandelli L, Schneider B, Hartmann AM, Schnabel A, Maurer K, Moller HJ, Serretti A. NOS-I and -III gene variants are differentially associated with facets of suicidal behavior and aggression-related traits. Am I Med Genet B Neuropsychiatr Genet. 2008;147B(1):42-8.

\section{Ready to submit your research? Choose BMC and benefit from:}

- fast, convenient online submission

- thorough peer review by experienced researchers in your field

- rapid publication on acceptance

- support for research data, including large and complex data types

- gold Open Access which fosters wider collaboration and increased citations

- maximum visibility for your research: over $100 \mathrm{M}$ website views per year

At BMC, research is always in progress.

Learn more biomedcentral.com/submissions 